Volume 7, No. 11 November 2019

International Journal of Emerging Trends in Engineering Research

Available Online at http://www.warse.org/IJETER/static/pdf/file/ijeter147112019.pdf

https://doi.org/10.30534/ijeter/2019/147112019

\title{
Design and Analysis of Heterogeneous Hybrid topology for VLAN configuration
}

\author{
S. Raja Gopal, P. Saleem Akram, S. Sriram, T. Pavan Koushik, V. Mohana Krishna \\ raja.dot.a@kluniversity.in , saleemakramp@gmail.com, sriramsankaramanchi85@gmail.com, \\ josephpavan8@gmail.com,mvkrishna675@gmail.com \\ Department of Electronics and Communication Engineering \\ Koneru Lakshmaiah Education Foundation, \\ Vaddeswaram, Guntur dist. \\ Andhra Pradesh, India
}

\begin{abstract}
In order to design a system like Hybrid topology, we should first know about different topology's and there functions and how they should be mainly arranged accordingly to our requirement. Some of the main concepts to be known are written below in keywords. It mainly includes emails, online banking, chats and other vital internet services which we use as a primary daily routine. As we all know that today's world is the age of innovation and connectivity, among it computer network has a very important role to play. One of Computer Network's positive and the most attractive feature is that to access a file without any physical connection or touching the computer.

In order to achieve reliability and performance, we should consider the best way to connect end to end or user to user of devices together which is also known as topology design. It has a most significant impact in designing a network. We should now design a network with a network simulator method, i.e., in this paper. We are concentrating on a heterogeneous hybrid topology for VLan to understand different concepts like topology design.
\end{abstract}

Key words: Cisco Packet Tracer (CPT); Router; Dynamic Host Configuration Protocol (DHCP); Domain name System (DNS); Route Information Protocol (RIP); Personal Computer (PC); Laptop; Star Topology; Tree Topology; Bus Topology.

\section{INTRODUCTION}

Cisco Packet Tracer (CPT): Cisco Packet Tracer[1][2] has two modes namely Physical mode and Logical mode. This Packet Tracer is a Cisco Systems-designed cross-platform visual simulation tool that enables all the users to create their own network topologies and simulate according to modern computer networks. This software allows all users to use a graphical command line interface to simulate the setup of Cisco routers [3] and switches. It is a drag and drop interface which includes to configure IP address of routers, switches, PC and many more. In this we can configure switches in two different ways. Firstly, by writing some commands in CLI which is Command Line Interface and the other way is by giving IP address to the external devices which are connected for the switch. As Packet Tracer is flexible it allows users to add or it allow user to remove virtual network devices. IOT[22][24] , Antennas[20][23], Wireless Networks[26][27] Acts as a major source while implementing this model.

Routing Information Protocol: Router Information Protocol is an older protocol which is rarely used now a days in CISCO or network burst test. It is a protocol of application layer and used for routing data packets by finding the best hop count. Compare with newer protocols today every protocol concentrates on time. So, while concentrating on time router may get over traffic. As a result it will lower down the performance of the system. So through this we can neglect over traffic issues. Any router may have more than one path and for every router there are many routers or many devices connected to it.

By the technique of hop count we can find number of steps we can reach from sender to receiver. Hop's are nothing but routers or devices form where data packets can move through. In a cloud there are many number of paths through which data can be transferred. In RIP, there might be congestion so it is not widely used. As a result it may get slower down.

Dynamic Host Configuration Protocol (DHCP): Dynamic Host Configuration Protocol is used for designing unique IP address to the host. It is used to provide different types. Subnet mask, which is used for finding that the host is present in the network or not. Sub net mask is used.
1) Router Address
2) DNS Address
3) Class Identifier

If we consider a network where we should used Ip addresses for systems or pc's that IP address should be unique. If it doesn't give unique Ip address total system becomes useless. For an example take two systems PC1, PC2 if those two systems are not given different IP addresses, the data coming through it doesn't understand to go towards a particular system and the systems gets corrupted. According 
S. Raja Gopal et al., International Journal of Emerging Trends in Engineering Research, 7(11), November 2019, 487 - 491

to our example, as we took two pc's, we assign Ip addresses manually. But in case where there are many pc's or devices it is difficult to assign, so DHCP is used.

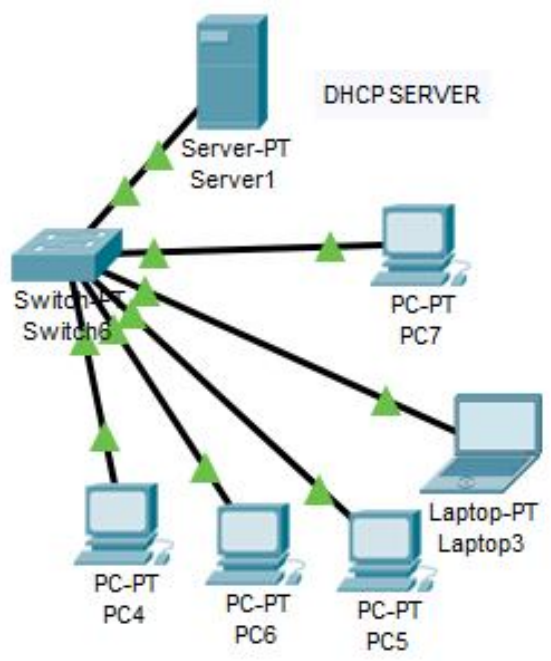

Figure 1: DHCP message format

In the above Fig.1 DHCP server and many PC's and a laptop is being connected to a switch.

Here DHCP checks and ensures that all other are assigned with different or an unique IP addresses.

Domain Name System: DNS is a database[11] [12] where we can store amount data and with a hierarchal structure.

In DNS total work depends on lower level performing devices, which operates on local information, rather than any other commanding influences.

It is used for mapping domain names to its ip addresses. Due to its ability to store more data. It is used as phone directory. It has an additional feature to add or to update.

For an example, www.ABC.com is a domain name and it can be transformed to 192.168.10.1 in DNS. If DNS server find any incorrect mapping at higher level as DNS server is a hierarchal structure it forwards the request to its following next level in it until we get correct query for it. DNS is used to get name when we give IP address.

Generally through DNS we can get the IP address if any URL is given.

\section{SYSTEM MODEL}

Cisco packet tracer is used to implement the following network.

There are the following steps:

1.)In order to implement the particular network we should create the topology which we need to.

2.)As we are using hybrid topology, we should take networking devices like switches, end to end devices, routers and connections to connect between switches to routers or routers to any end devices.
Table 1: List of specification

\begin{tabular}{|l|l|}
\hline DEVICE & SPECIFICATIONS \\
\hline Router & 2 serial ports \\
\hline $\begin{array}{l}\text { Switch and other } \\
\text { devices }\end{array}$ & $\begin{array}{l}24 \text { fast Ethernet ports, } \\
\text { laptops, PC and server }\end{array}$ \\
\hline Hub & 6 ports \\
\hline Connections & $\begin{array}{l}\text { Serial DCE, Copper } \\
\text { Cross over cable }\end{array}$ \\
\hline
\end{tabular}

3.) Connections: We used 3-types
1.)Serial DCE
2.)Copper Straights through
3.)Copper cross over

1.)Serial DCE: There are used between to any routers.

2.) Copper Straights through: Copper Straight through are used to connect from routers to PC.

3.) Copper cross over: Copper cross over cables are used between two Hub to switch or from switch to switch.

In order to configure routers there are only two ways.

1.) Executing commands in CLI

2.) Configuring router

In this we have used both ways configuration routers.

Total system model is being connected like a ring topology but total model is been divided into various model's or region's. They are:

Table 2: Reason wise specification

\begin{tabular}{|l|l|}
\hline Region 1 & Tree topology \\
\hline Region 2 & DHCP \\
\hline Region 3 & DNS \\
\hline Region 4 & Star topology \\
\hline Region 5 & BUS topology and Router direct \\
\hline Region 6 & $\begin{array}{l}\text { PConnection } \\
\text { cond }\end{array}$ \\
\hline
\end{tabular}

Figure 2: Implementation of Hybrid topology using various topology's 
From figure 2 there are six regions and every region is of different purpose. Each of the region have different functionality

\section{Tree Topology}

In region 1 we have used tree topology which can be seen in Fig.4. Tree topology is which where there are many branches in the form of PC's which are connected to different level switches.

In this topology, it requires large amount of network and there are many interconnections between them. If one node is failed the remaining child node of that fault node can not be accessed.

It is costly due to it's huge network and it is easy to configure if parent nodes are known.

\section{Bus Topology}

Bus topology is used in region 5. It contains a hub attached to it. Performance depends upon the Hub. As it depends on Hub, if Hub fails total network fails and if Hub works the remaining depends upon the things after Hub. Drop Line is used in Bus topology for the interconnections. It is easy to configure and to connect.

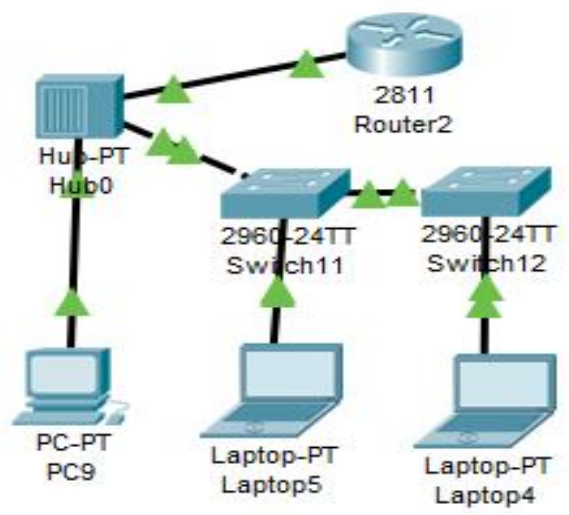

Figure 3: Bus Topology

From the Figure 3 we have seen how Hub is the center of network in Bus topology and it's importance in the Figure 2.

\section{Router Configuration}

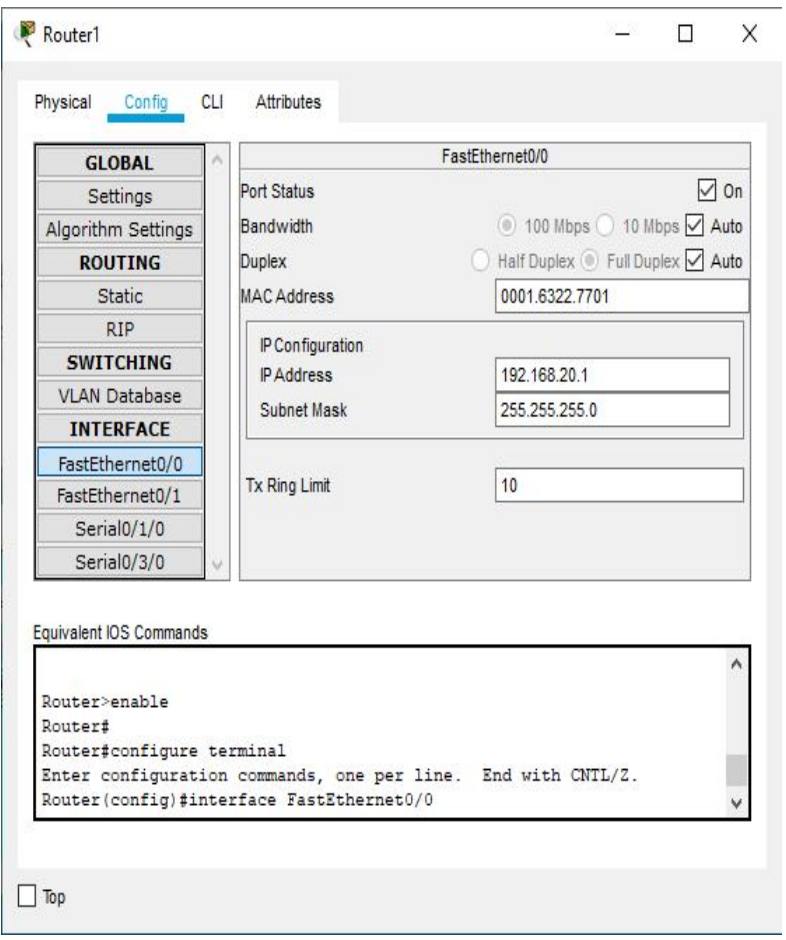

Figure 4: Router configuration

Router configuration is done through a process which involve mainly two steps:

1. IP address should be given to router in config, which we can see in the above Fig.4. Those configurations should be considered according to the interface.

2. Router to Router connection is another impact full thing which should be taken into consideration. From Figure 2 Router to Router's are connected with Serial DCE which is in red color. 


\section{RESULTS}

By the process, this is how we can get access to any page through IP address and DHCP is a protocol (figure 5) which access the web page through IP address.

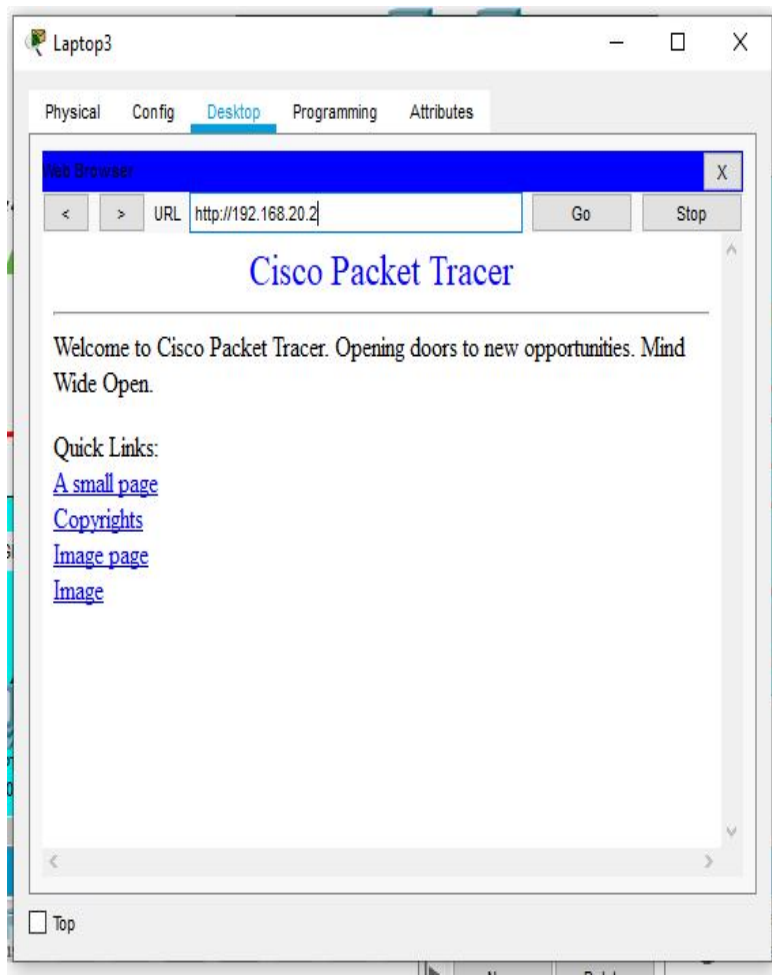

Figure 5: Accessing through IP address in DCHP

\section{CONCLUSION}

Totally through this paper, we implemented Hybrid, Tree, Star and Bus topologies and a part from those we also used DHCP and DNS in system model using Cisco Packet Tracer. We used Routing Information Protocol, in order to find the path of packet. It is a simple and easily configurable protocol. It is considered to performs well for small scale network. We used both DHCP and DNS in same network as DNS is used for mapping domain name to ip address and DHCP to assign Ip address. Through this we can transmit data without any delay and transmitting.

\section{REFERENCES}

[1] Janitor, J,; Jakab, F.; Kniewald, K., "Visual Learning Tools for Teaching/Learning Computer Networks: Cisco Networking Academy and Packet Tracer," Networking and Services (ICNS), 2010 Sixth International Conference on , vol., no., pp.351,355, 7-13 March 2010. https://doi.org/10.1109/ICNS.2010.55
[2] Petcu, D.; Iancu, B.; Peculea, A.; Dadarlat, V.; Cebuc, E., "Integrating Cisco Packet Tracer with Moodle platform: Support for teaching and automatic evaluation," Networking in Education and Research, 2013 RoEduNet International Conference 12th Edition , vol., no., pp.1,6, 26-28 Sept. 2013 https://doi.org/10.1109/RoEduNet.2013.6714190

[3] CCNA by Todd Lammle, 5th edition

[4] Al-Mekhlafi, Z.G.; Hassan, R., "Evaluation study on routing information protocol and dynamic source routing in Ad-Hoc network," Information Technology in Asia (CITA 11), 2011 7th International Conference on, vol.no., pp.1,4, 12-13 July 2011 https://doi.org/10.1109/CITA.2011.5999535

[5] Bin Wang; Jian-hui Zhang; Wen-ping Chen; Yun-fei Guo,"A Fast Reroute Mechanism for RIP Protocol," Circuits, Communications and Systems, 2009. PACCS '09. Pacific-Asia Conference on , vol., no., pp.74,77, 1617 May 2009

[6] Detection of Invalid Routing Announcements in the RIP Protocol", D. Pei, D. Massey, and L. Zhang, IEEE Global Communications Conference (Globecom), December, 2003

[7] A Path-Finding Algorithm for Loop-Free Routing, J.J. Garcia-Luna-Aceves and S. Murthy, IEEE/ACM Transactions on Networking, February 1997

[8] Massner, S.; Weber, T., "A Dynamic Host Configuration Protocol Based Service Discovery Mechanism," Computer Software and Applications Conference Workshops (COMPSACW), 2011 IEEE 35th Annual , vol., no., pp.62,67, 18-22 July 2011

[9] Massner, S.; Weber, T., "A Dynamic Host Configuration Protocol Based Service Discovery Mechanism," Computer Software and Applications Conference Workshops (COMPSACW), 2011 IEEE 35th Annual, vol., no., pp.62,67, 18-22 July 2011

[10] Title, Data Communications \& Networking (sie) McGraw-Hill Forouzan networking series. Author, A. Behrouz Forouzan. Publisher, McGraw-Hill Education (India)

[11] Gao, H.; Yegneswaran, V.; Jiang, J.; Chen, Y.; Porras, P.; Ghosh, S.; Duan, H., "Reexamining DNS From a Global Recursive Resolver Perspective," Networking, IEEE/ACM Transactions on , vol.PP, no.99, pp.1,1

[12] Chul-Jin Park; Seong-Jin Ahn; Jin-Wook Chung; Choon-Hi Lee; Chang-Soon Park, "The improvement for integrity between DHCP and DNS," High Performance Computing on the Information Superhighway, 1997.HPC Asia '97, vol., no., pp.511,516, 28 Apr-2 May 19

[13] Rao, K. R., Kumar, T. R., \& Venkatnaryana, C. "Selection of anchor nodes in time of arrival for 
S. Raja Gopal et al., International Journal of Emerging Trends in Engineering Research, 7(11), November 2019, 487 - 491

localization in wireless sensor networks" doi:10.1007/978-81-322-2671-0_5 (2016).

[14] Sahiti, V., Raghava Rao, K., \& Mohan Rao, K. R. R. "Hashing technique data optimization for low power consumption in wireless sensor network". Indian Journal of Science and Technology, 9(17) doi:10.17485/ijst/2016/v9i17/93101,2016.

[15] Abdul A.M., Krishna B.M., Murthy K.S.N., Khan H., Yaswanth M., Meghana G., Madhumati G.L., "IOT based home automation using FPGA", Journal of Engineering and Applied Sciences, Vol: 11, Issue: 9, pp: 1931 - 1937, ISSN 1816949X ,2016

[16] Narayana M.V., Dusarlapudi K., Uday Kiran K., Sakthi Kumar B., "IoT based real time neonate monitoring system using Arduino",2017 Journal of Advanced Research in Dynamical and Control Systems,Vol:9, issue:Special issue 14,pp: 1764-1772,DOI: ,ISSN: 1943023X

[17] Gadde S.S., Ganta R.K.S., Gopala Gupta A.S.A.L.G., Raghava Rao K., Mohan Rao K.R.R..," Securing Internet of Things(IoT) using honeypots“, 2018, Microsystem Technologies , Vol: 24 ,Issue : 3,pp:1609 to:: 1614 ,DOI: 10.1007/s00542-017-3563-x, ISSN: 9467076

[18] Ravikanth, B., Akram, P. S., Ashlesha, V., \& Ramana, T. V. (2017). "Tuning operating frequency of antenna by using metasurfaces". Paper presented at the International Conference on Signal Processing, Communication, Power and Embedded System, SCOPES 2016 Proceedings, 2064-2068. doi:10.1109/SCOPES.2016.7955811

[19] Gopi Krishna P., Srinivasa Ravi K., Hareesh P., Ajay Kumar D., Sudhakar H. ., " Implementation of bi-directional blue-fi gateway in IoT environment ", 2018, International Journal of Engineering and Technology(UAE), Vol: 7 ,Issue: ,pp: 733 to:: 738 ,DOI: ,ISSN: 2227524X

[20] Saleem Akram, P., \& Ramana, T. V.(2019). "Two dimensional beam steering using active progressive stacked electromagnetic band gap ground for wireless sensor network applications". Journal of Computational and Theoretical Nanoscience, 16(5-6), 2468-2478. doi:10.1166/jctn.2019.7918

[21] Muzammil Parvez M., Shanmugam J., Mohan Rao K.R.R., Lakshmana C., Shameem S. .," Alive node and network lifetime analysis of DEEC protocol and EDDEEC protocol “, 2018, International Journal of Engineering and Technology(UAE), Vol: 7 ,Issue: ,pp: 661 to:: 664 ,DOI: ,ISSN: 2227524X

[22] Pavithra T., Sastry J.K.R. .," Strategies to handle heterogeneity prevalent within an IOT based network ", International Journal of Engineering and Technology(UAE), Vol: 7 ,Issue: 2 ,pp: 203 to::
208 ,DOI: $10.14419 /$ ijet.v7i2.7.10293 ,ISSN: 2227524X, 2018

[23] Devi Susmitha, N., Sowmya, S., Akram, P. S., \& Ramana, T. V. (2017). " Tuning of L-C meta-material structure for antenna applications". Paper presented at the International Conference on Signal . Processing, Communication, Power and Embedded System, SCOPES 2016

Proceedings,1845-1850.doi:10.1109/SCOPES.201 6.7955764

[24] Poonam Jain S., Pooja S., Sripath Roy K., Abhilash K., Arvind B.V. .," Implementation of asymmetric processing on multi core processors to implement IOT applications on GNU/Linux framework ", 2018, International Journal of Engineering and Technology(UAE), Vol: 7 ,Issue: 1.1 ,pp: 494 to:: 499 ,DOI: ,ISSN: $2227524 \mathrm{X}$

[25] Rambabu K., Venkatram N. .," Traffic flow features as metrics (TFFM): "Detection of application layer level DDOS attack scope of IOT traffic flows “, 2018, International Journal of Engineering and Technology(UAE) ,Vol: 7 ,Issue: 1.1 ,pp: 554 to:: 559 ,DOI: ,ISSN: 2227524X

[26] Bhatt, P., Akram, P. S., \& Ramana, T. V. (2015). "A novel on smart antennas to improve performance in wireless communications". Paper presented at the International Conference on Signal Processing and Communication Engineering Systems - Proceedings of SPACES 2015, in Association with IEEE,187-190.doi:10.1109/SPACES.2015.705824 5

[27] Saleem Akram, P., \& Venkata Ramana, T. (2019). "A novel approach of microstrip fed planar monopole antenna for wsn applications at 2.4ghz ism band" . International Journal of Scientific and Technology Research, 8(8), 665-669.

[28] Anuka Pradhan, Biswaraj Sen "A brief study on Contention Based Multi-Channel MAC Protocol for MANETs", International Journal of Emerging Trends in Engineering Research (IJETER), Vol 6, No 12, pp 74-78, Dec 2018

https://doi.org/10.30534/ijeter/2018/016122018

[29] Kyeongjoo Kim, Jihyun Song, Minsoo Lee " Real-time Streaming Data Analysis using Spark", International Journal of Emerging Trends in Engineering Research (IJETER), Vol 6, No 1, pp 1-5, Jan 2018.

https://doi.org/10.30534/ijeter/2018/01612018 